\section{Effect of $\gamma$-radiation on Radionuclide Retention in Compacted Bentonite}

Michael Holmboe*, Knapp Karin Norrfors, Mats Jonsson and Susanna Wold

KTH School of Chemical Science and Engineering

Nuclear Chemistry, Royal Institute of Technology

SE-100 44 Stockholm, Sweden

*Corresponding author.

E-mail: holmboe@kth.se (M. Holmboe)

Tel: +4687908789 .

Fax: +4687908772.

\begin{abstract}
Compacted bentonite is proposed as an engineered barrier in many concepts for disposal of high level nuclear waste. After the initial deposition however, the bentonite barrier will inevitably be exposed to ionizing radiation (mainly $\gamma$ ) under anoxic conditions. Because of this, the effects of $\gamma$-radiation on the apparent diffusivity values and sorption coefficients in bentonite for $\mathrm{Cs}^{+}$and $\mathrm{Co}^{2+}$ were tested under different experimental conditions. Radiation induced effects on sorption were in general more noticeable for $\mathrm{Co}^{2+}$ than for $\mathrm{Cs}^{+}$, which generally showed no significant differences between irradiated and unirradiated clay samples. For $\mathrm{Co}^{2+}$ however, the sorption to irradiated MX80 was significantly lower than to the unirradiated clay samples regardless of the experimental conditions. This implies that $\gamma$-radiation may alter the surface characteristics contributing to surface complexation of $\mathrm{Co}^{2+}$. With the experimental conditions used however, the effect of decreasing sorption was not large enough to be reflected on the obtained $D_{a}$ values.
\end{abstract}

\section{Introduction}

Most concepts for a high level nuclear waste repository (HLNW) involve both natural and engineered barriers in deep geological formations. In a typical HLNW repository such as the Swedish KBS-3 concept, compacted bentonite will be used as a transport barrier for radionuclides ( $\mathrm{RN})$ released from the nuclear waste. The rationale for using bentonite is its dense microstructure and swelling capacity in compacted form, rendering diffusion as the only way of transport from or to the canister holding the nuclear waste, as well as the high sorption capacity for many radionuclides. Previous studies have shown that the diffusive transport of radionuclides in water saturated compacted bentonite under ambient conditions is governed by several different parameters, such as compaction, smectite content, ionic strength and the specific interactions between the diffusants and montmorillonite, the main component of bentonite (Eriksen et al., 1999; Kozaki et al., 1998; 2001; Molera and Eriksen,
2002; Van Loon et al., 2007). Under repository conditions however, the bentonite barrier will inevitably be exposed to ionizing radiation (mainly $\gamma$ from Cs-137) under anoxic conditions. Previous studies concerning $\gamma$-irradiation of bentonite with low water contents (Huang and Chen, 2004; Negron et al., 2002; Plötze, 2003; Plötze et al., 2002; Pusch et al., 1993; Pushkareva et al., 2002), have only found small or insignificant effects on both the physical and chemical properties of bentonite and montmorillonite, even at very high doses (several MGy, $1 \mathrm{~Gy}=1 \mathrm{~J} / \mathrm{kg}$ ). However, in two previous studies, (Holmboe et al., 2011; Holmboe et al., 2009) radiation induced effects manifested as increased structural $\mathrm{Fe}(\mathrm{II}) / \mathrm{Fe}_{\mathrm{Tot}}$ ratio and increased colloid stability, respectively, were found. To the best of our knowledge, no study investigating radionuclide diffusion has yet focused on the effects of ionizing radiation on montmorillonite. In this work we have studied the effects of $\gamma$-radiation on sorption and apparent diffusivities in bentonite, under anoxic and oxic conditions. Since diffusion of $\mathrm{Co}^{2+}$ and $\mathrm{Eu}^{3+}$ through compacted saturated bentonite has been shown to be enhanced in the presence of humics (Wold and Eriksen, 2007) and since native bentonite contains various accessory minerals, both Wyoming Bentonite MX-80 and homo-ionic Na-montmorillonite, with or without addition of humics were probed in the diffusion experiments. In order to specifically study the effect of ionizing radiation on the sorption coefficients, $K_{d}$, separate batch sorption experiments were also undertaken.

\section{Experimental section}

\subsection{Materials}

The bentonite clay which was used in this study without further treatment was the widely studied Wyoming Bentonite MX-80 (MX80) with a montmorillonite content of $\sim 82 \%$. The exchangeable cations for this bentonite are approximately: 74.8\% $\mathrm{Na}^{+}, 16.7 \% \mathrm{Ca}^{2+}, 6.7 \% \mathrm{Mg}^{2+}$, and $2 \% \mathrm{~K}^{+}$. (Karnland et al., 2006). In order to avoid possible effects of the accessory minerals, a purified Na-montmorillonite originating from the montmorillonite reference clay Wyoming Montmorillonite Swy-2 (supplied by the Clay Mineral society, hereafter denoted as $\mathrm{SwyNa}_{w}$ ) was also used in the diffusion experiments. This clay was obtained by i) $\mathrm{Na}^{+}$-exchange by repeated washing with $0.5 \mathrm{M} \mathrm{Na}_{2} \mathrm{SO}_{4}$ ii) Removal of free iron oxides by a Citrate-Bicarbonate (CB) treatment. iii) Organic residues and remaining citrate was removed by addition of 2 $\mathrm{M} \mathrm{H}_{2} \mathrm{O}_{2}$ at $70{ }^{\circ} \mathrm{C}$ and stirring for 6 hours. iv) Excess carbonates were removed by stirring the suspension at $70{ }^{\circ} \mathrm{C}$ at $\mathrm{pH} 1$ after addition of $\mathrm{H}_{2} \mathrm{SO}_{4}$ for 6 hours. Finally the $\mathrm{pH}$ of the suspension was neutralized by addition of small aliquots of $\mathrm{NaOH}$. The remaining dispersion was then dried at $120^{\circ} \mathrm{C}$ and 
grinded to a fine powder. Due to concern with the CB treatment affecting the montmorillonite surface charge and solubility (Stucki et al., 1984) of the SwyNaw clay, experiments both $\mathrm{Na}$ and Ca-montmorillonite originating from Wyoming Bentonite MX-80 were also used, hereafter denoted as $\mathrm{WyNa}$ and $\mathrm{WyCa}$, respectively. These clay materials were diluted with $1 \mathrm{M} \mathrm{NaCl}$ and left to settle where after the supernatant was removed. The washing procedure was repeated three times where after the clay dispersions were washed and transferred to dialysis membranes and placed in de-ionized water, which was exchanged until the conductivity was below $10 \mu \mathrm{S} / \mathrm{cm}$. After a final sedimentation step in order to remove the $>2 \mu \mathrm{m}$ fraction, the washing and dialysis cycle was repeated with either $1 \mathrm{M} \mathrm{NaCl}$ or $\mathrm{CaCl}_{2}$ where after the clays were dried at $60{ }^{\circ} \mathrm{C}$ (Karnland et al., 2006).

The humic substance used in this study was a commercial humic standard (1S102) supplied by the International Humic Substances Society. This humic (HS) was dissolved in $\mathrm{NaOH}$ at pH 13 under stirring and neutralized by $\mathrm{H}_{2} \mathrm{SO}_{4}$ to a $\mathrm{pH}$ of $\sim 7$.

In order to study the impact of $\gamma$-irradiation on weakly sorbing and strongly sorbing tracers in the sorption and diffusion experiments, the radioactive tracers used in this study were ${ }^{137} \mathrm{Cs}^{+}$and ${ }^{60} \mathrm{Co}^{2+}$ (supplied by Isotrak $^{\mathrm{TM}}$ ), respectively, together with $1 \mu \mathrm{M}$ inactive carrier isotopes.

\subsection{Batch sorption experiments}

In the batch sorption experiments, samples of $0.090 \mathrm{~g}$ clay and a total volume of $18 \mathrm{~mL}$ were used to get a volume to mass ratio of 200 . In order to qualitatively investigate the effect of $\gamma$-radiation as dependent on water saturation, anoxic/oxic conditions as well as influence of HS, duplicates of different samples were either unirradiated or irradiated, with a $\gamma$-dose of approx. 60kGy using a Gammacell 1000 Elite ${ }^{137} \mathrm{Cs}$-source. All glassware and equipment used in the experiments was washed in $1 \%$ nitric acid prior the experiments. The samples were either irradiated under inert $\left(\mathrm{N}_{2}\right)$ or ambient conditions, either as completely dry or after full water saturation, with or without the presence of $0.1 \mathrm{~g} / \mathrm{L}$ humic substances in the solutions. Since certain radiation induced effects in the montmorillonite such as changes in the structural Fe(II)/Fe(III) ratio (Holmboe et al., 2011) is oxygen sensitive, one set of samples was kept in a glove box with an oxygen concentration of $\sim 5 \mathrm{ppm}$. Table 1 summarizes the different combinations of sample setups in the batch sorption experiments. All samples were prepared in duplicates.

Since the sorption of radionuclides is $\mathrm{pH}$ dependent, the $\mathrm{pH}$ was adjusted to approx. 9 by adding a borate buffer. According to speciation calculations using the software MEDUSA, in combinations with experiments with samples without buffer at the same $\mathrm{pH}$, and the literature, the borate do not affect the system, Table 2. The electrolyte concentration was adjusted to $0.05 \mathrm{M} \mathrm{Na}_{2} \mathrm{SO}_{4}$, i.e. $0.1 \mathrm{M} \mathrm{Na}^{+}$, and the radioactive tracers together with an inactive carrier with a concentration of $1 \mu \mathrm{M}$ were added to all samples. After 5 days of equilibration, the clay suspensions were centrifuged for $30 \mathrm{~min}$ at $6000 \mathrm{rpm}$ and the activity in the supernatants as analyzed quantitatively with $\gamma$-spectrometry.

Two reference samples without clay were prepared with the same procedure as the clay samples and were later used as references in the calculations of the sorbed amount of RN. The dissociation constants, $K_{d}$, for each sample were calculated from equation 1 .

$K_{d}=\frac{A_{i n}-A_{e q}}{A_{e q}} \cdot \frac{V}{m} \frac{\mathrm{cm}^{3}}{g}$

where $A_{i n}$ is the activity in the reference sample, $A_{\text {eq }}$ is the solution activity at equilibrium, $\mathrm{V}$ is the sample volume $\left[\mathrm{cm}^{3}\right]$ and $m$ is the mass of the clay in the sample [g].

Table 1. Summary of the samples in the batch sorption experiments. All samples were prepared in duplicates.

\begin{tabular}{l|c|ccc|cc|}
\multicolumn{1}{c}{ Clay } & Atm. & \multicolumn{3}{c}{$\gamma$-irradiated } & \multicolumn{2}{c}{ Unirradiated } \\
\hline MX-80 & $\mathrm{N}_{2}$ & dry & wet & wet $+\mathrm{HS}$ & wet & wet $+\mathrm{HS}$ \\
$\mathrm{Na} /$ Ca-Mont & $\mathrm{N}_{2}$ & dry & wet & wet $+\mathrm{HS}$ & wet & wet $+\mathrm{HS}$ \\
$\mathrm{Na} /$ Ca-Mont & Air & dry & wet & wet $+\mathrm{HS}$ & - & - \\
\hline
\end{tabular}

Table 2. Comparisons of $K_{d}$-values for the samples with and without buffer and due to literature.

\begin{tabular}{l|c|c|c}
\multicolumn{1}{c}{ Without buffer } & With buffer & \multicolumn{2}{c}{ Molera and Eriksen, } \\
\hline $\mathrm{pH}$ & 8.9 & 8.9 & 9.2 \\
Clay & MX80 unirradiated & MX80 unirradiated & MX80 unirradiated \\
$K_{d}\left[\mathrm{~cm}^{3} / \mathrm{g}\right]$ & 26411 & 12994 & 29178 \\
\hline
\end{tabular}

\subsection{Diffusion experiments}

In order to have similar montmorillonite density in the indiffusion experiment, Bentonite (MX80) and Namontmorillonite (SwyNaw) were compacted to dry density values of 1.6 and $1.5 \mathrm{~g} / \mathrm{cm}^{3}$, respectively, into diffusion cells made of PEEK (Polyetheretherketone), since this polymer material is known for its high resistance to ionizing radiation. The dimension of the clay plugs, which were confined by two PEEK filters, was $10 \times 5 \mathrm{~mm}$ in diameter and length, respectively. The diffusion setup is schematically shown in figure 1. The different diffusion samples with MX80 and SwyNa $\mathrm{w}_{\mathrm{w}}$ were generally prepared under same conditions as for the batch sorption experiments, except the diffusion cells samples were saturated and equilibrated with a $0.05 \mathrm{M}$ 
$\mathrm{Na}_{2} \mathrm{SO}_{4}$ solution for 6 weeks. Table 1 summarizes the 13 different sample types used in the diffusion experiment. After saturation, the radioactive tracers with $5 \mu \mathrm{M}$ inactive carrier isotope were added to the inlet solutions. During the diffusion experiment, sampling of the outlet solutions for $\gamma$-activity were drawn on a weekly basis during 80 days, where after the experiment was terminated and the clay plugs extruded and sliced into thin sections in order to obtain the tracer concentration profiles within the clay. This was achieved by gravimetric control of each slice and analyzing the activity quantitatively with $\gamma$-spectrometry.

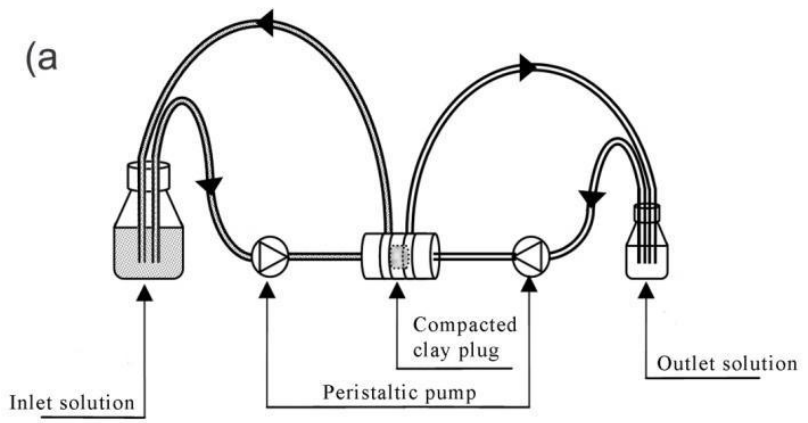

(b
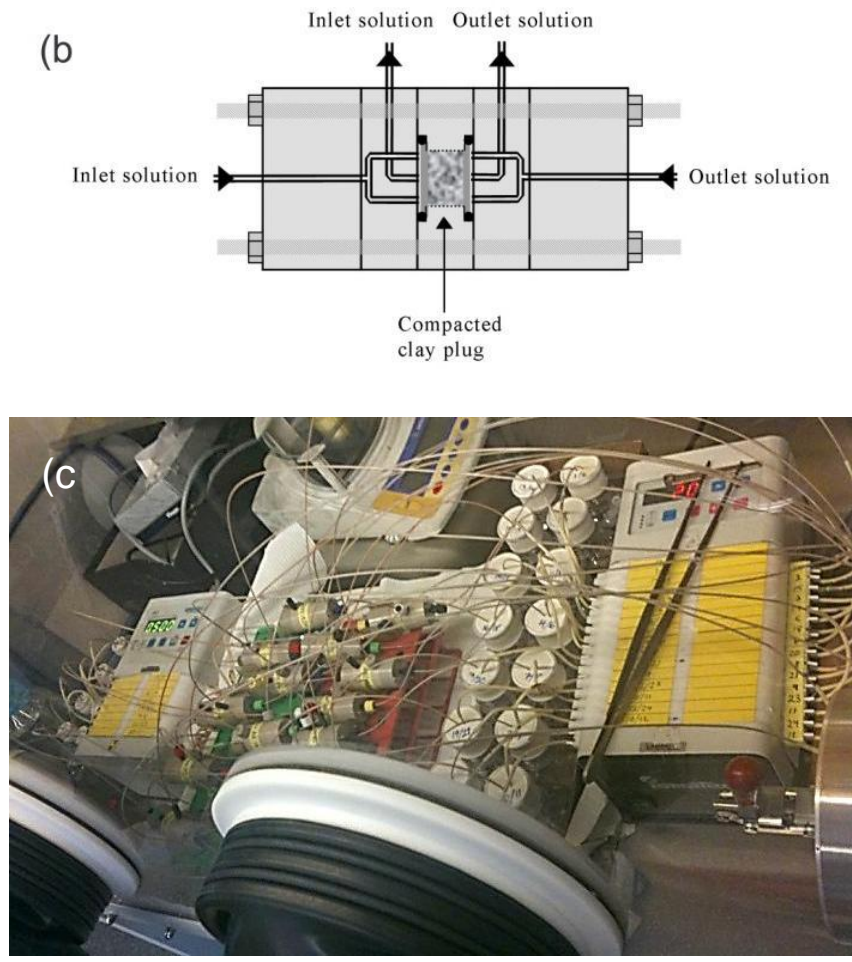

Figure 1. Illustration of the a) diffusion setup. b) an individual PEEK diffusion cell. c) Photo of the experimental diffusion setup with 16 PEEK cells, kept under $N_{2}$ atmosphere in a glove box.

\section{Results and discussion}

\subsection{Batch sorption results}

The $K_{d}$ values obtained from the batch sorption experiments for $\mathrm{Co}^{2+}$ and $\mathrm{Cs}^{+}$with the respective clay material are shown in Figure 2 and 3 respectively, and tabulated in the supplementary material (Table S.1).

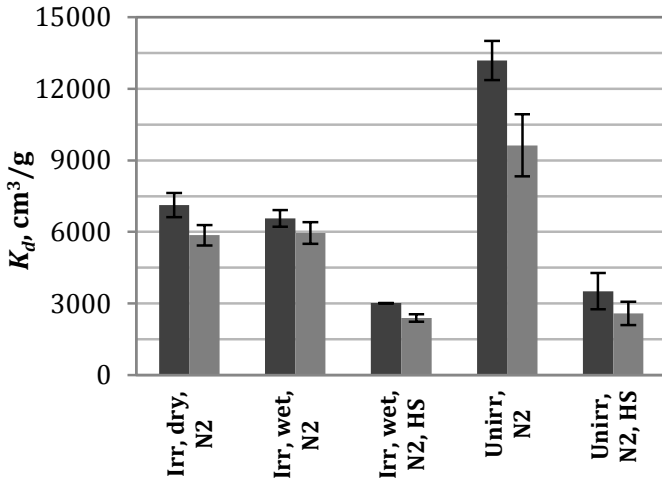

- MX80 $\mathrm{pH} 9$

MX80

$\mathrm{pH} 9$

$+\mathrm{Ca}$

b)

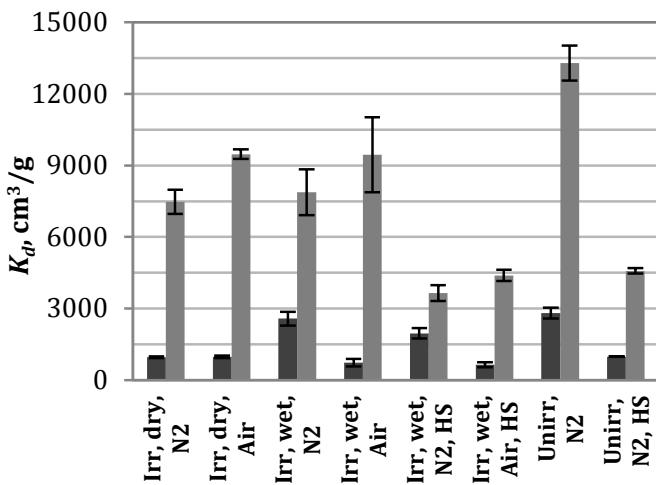

- WyNa

pH 9

- WyCa pH 9

C)

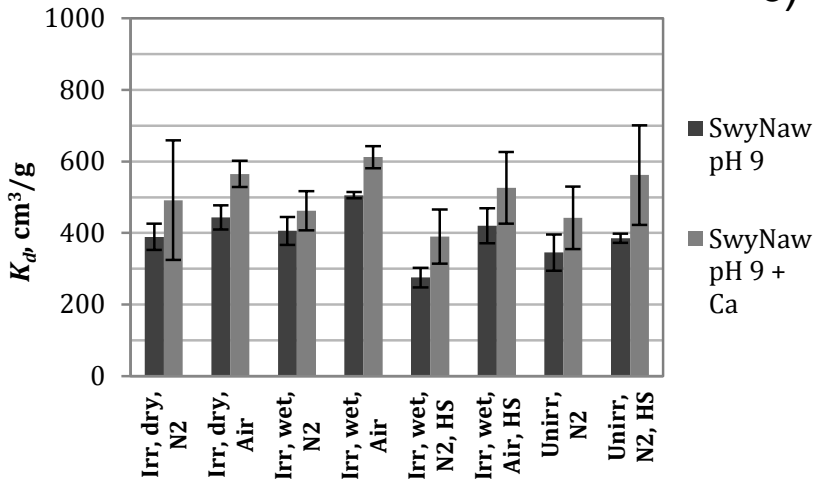

Figure 2. The $K_{d}$ values for $\mathrm{Co}^{2+}$ obtained for the different clay materials, a) MX80 b) WyNa and WyCa and c) SwyNaw. 


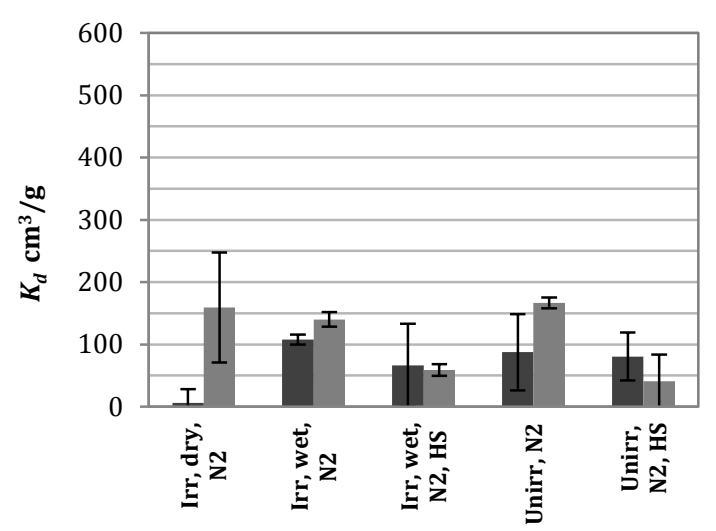

a)

\section{- MX80}

$\mathrm{pH} 9$

- MX80

$\mathrm{pH} 9+$

$\mathrm{Ca}$

b)

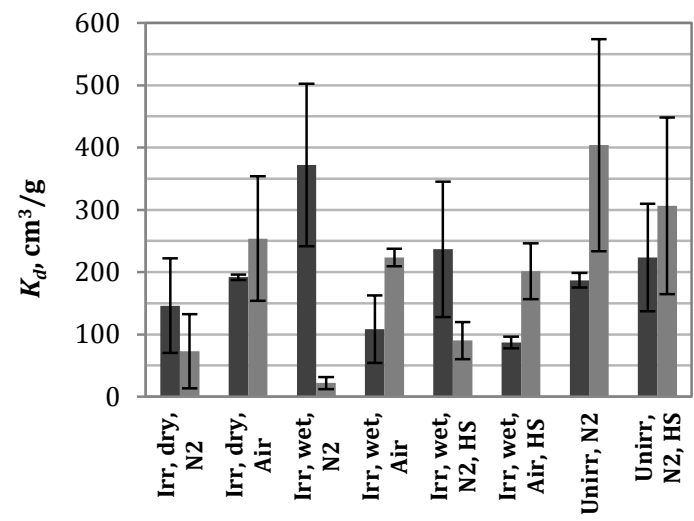

- WyNa

pH 9

- WyCa

pH 9

C)

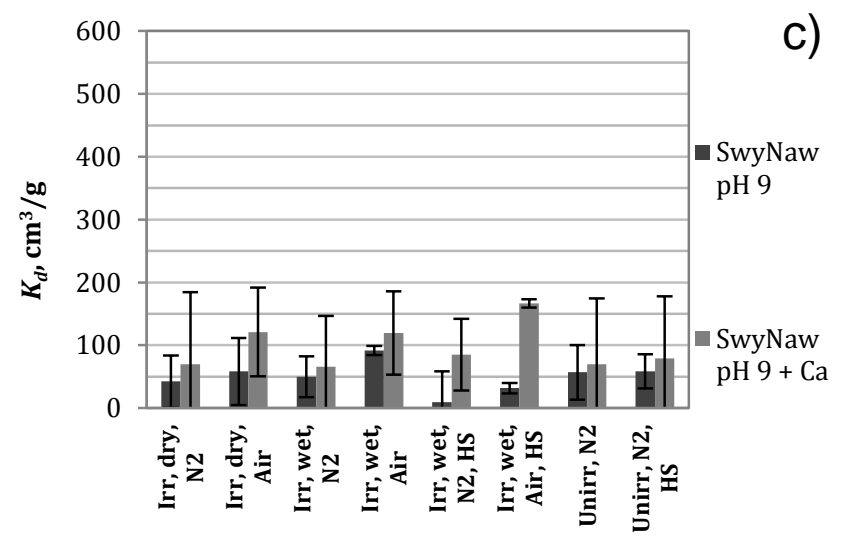

Figure 3. The $K_{d}$ values for $\mathrm{Cs}^{+}$obtained for the different clay materials, a) SwyNaw b) WyNa and WyCa and c) MX80.

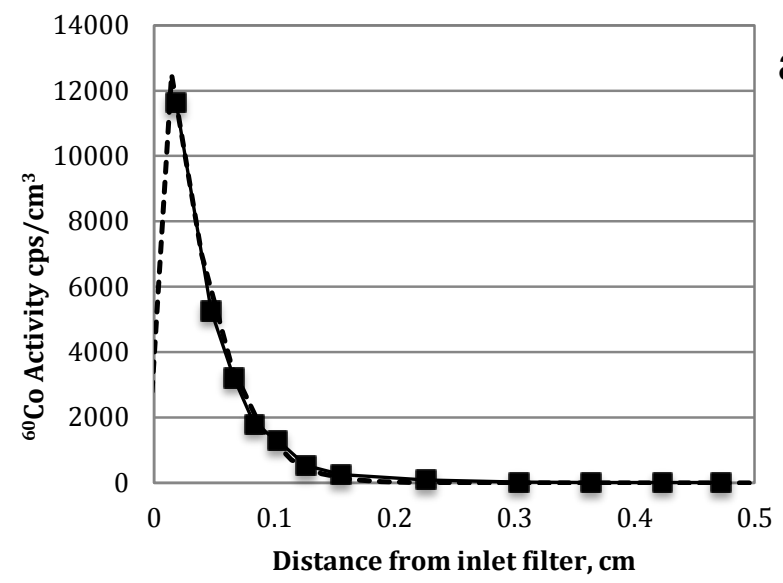

a)

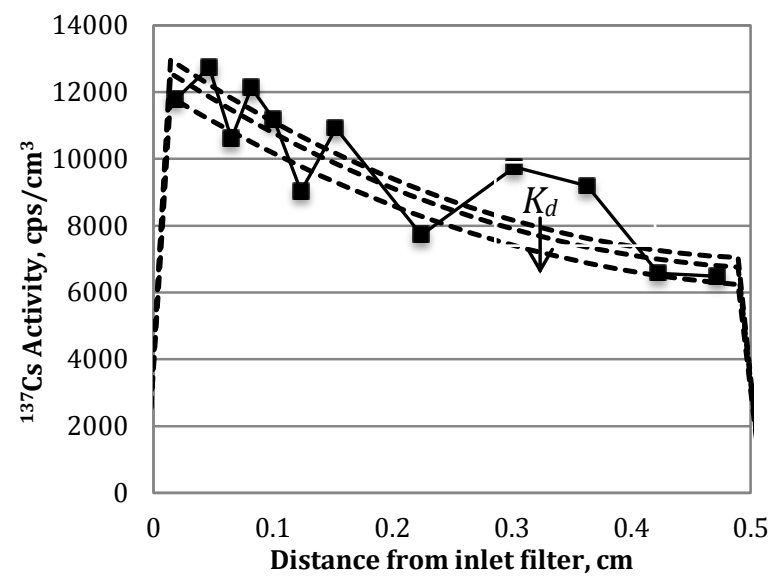

b)

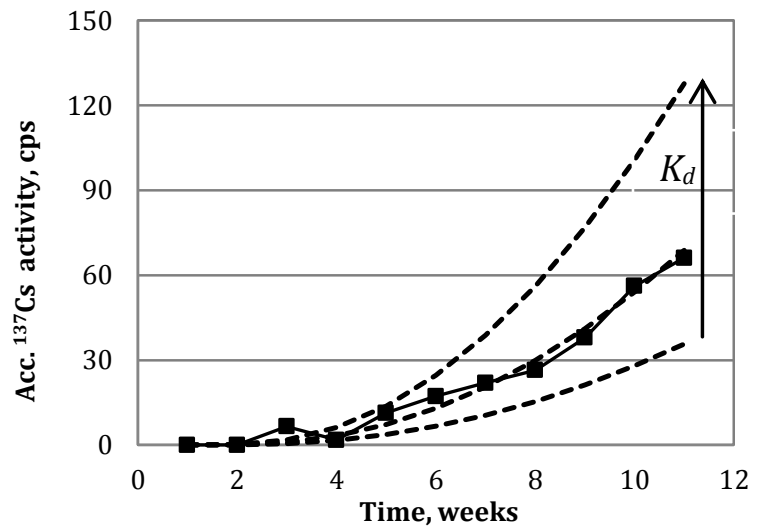

c)

Figure 4. Typical experimental and simulated diffusion data, here shown for the unirradiated MX80 sample saturated with HS, showing the concentration profiles in the clay plugs of: (a ${ }^{60} \mathrm{Co}^{2+}$, b) ${ }^{137} \mathrm{Cs}^{+}$. c) The breakthrough data for ${ }^{137} \mathrm{Cs}^{+}$. The different simulated dashed curves results from a variation in $K_{d}$ by a factor of 2 from the optimal fit (decreasing in the direction of the arrows). Note the insignificant change in a). 
For $\mathrm{Co}^{2+}$, the sorption to irradiated MX80 samples not containing HS was significantly lower, approx. $50 \%$ of the unirradiated clay samples regardless of the experimental conditions, see Figure 3a. A similar decrease in $K_{d}$ with approx. 30\% was also seen for the MX80 samples subjected to $\mathrm{Ca}^{2+}$ addition and the WyCa samples, see Figure $2 \mathrm{~b}$. In both the MX80 and the WyCa samples and in the presence of $\mathrm{HS}$, the $K_{d}$ value of $\mathrm{Co}^{2+}$ was further reduced by approx. $70 \%$ and irrespective of irradiation, compared to the unirradiated reference sample not containing HS. This effect can be explained by complexation of $\mathrm{Co}^{2+}$ to the humic particles, which increase the $\mathrm{Co}^{2+}$ concentration out in solution significantly, since the HS was not separated by centrifugation. A similar effect of HS was also seen in the WyNa samples, with the WyNa sample irradiated under anoxic conditions being the exemption. Also for the irradiated WyNa samples without HS, a general decrease of $K_{d}$ was found, although the $K_{d}$ values were significantly lower compared to the corresponding MX80 and WyCa samples. This decrease was especially found in the samples irradiated under dry conditions (33\%) as well as under wet ambient conditions (25\%). However, no detectable effect could be seen between the irradiated and unirradiated sample under anoxic conditions. In the SwyNa $\mathrm{w}_{\mathrm{w}}$ clay, pretreated with the CB method and $\mathrm{H}_{2} \mathrm{O}_{2}$, relatively low $K_{d}$ values was found compared to the corresponding $K_{d}$ values obtained with WyNa or MX80, see Figure 2a and 3c, and no significant change due to the different treatments could be found. For $\mathrm{Cs}^{+}$, less significant radiation induced effects was found, likely since the clay affinity for $\mathrm{Cs}^{+}$is lower than for $\mathrm{Co}^{2+}$. As can be seen in Figure 3a and Figure 3b, with both for MX80 and WyNa, no apparent difference in sorption of $\mathrm{Cs}^{+}$was found upon irradiation. However, for the WyCa material, a small decrease in the $K_{d}$ values for samples irradiated under anoxic conditions was found. Also, addition of HS appeared to bring more $\mathrm{Cs}^{+}$out to the solution, significantly decreasing the $K_{d}$ values, though not to the same extent as with $\mathrm{Co}^{2+}$. As for the samples subjected to a small $\mathrm{Ca}^{2+}$ addition, in the MX80 samples and especially in the case of $\mathrm{Co}^{2+}$, the extra addition of $\mathrm{Ca}^{2+}$ seemingly reduced the $K_{d}$ value. This was contrary to the SwyNa $\mathrm{w}_{\mathrm{w}}$ samples were an increase in $K_{d}$ upon $\mathrm{Ca}^{2+}$ addition was found. The difference between the SwyNaw clay and the WyNa clay cannot be explained at this moment. However, it is interesting to note that irradiation of $\mathrm{WyNa}$ under oxic conditions (see Figure $2 \mathrm{~b}$ and Figure $3 \mathrm{~b}$ ) as well as treatment with $\mathrm{H}_{2} \mathrm{O}_{2}$ reduces the sorption capacity of the clays, suggesting that the $\mathrm{H}_{2} \mathrm{O}_{2}$ impede montmorillonites sorption capacity.

Hence, more obvious radiation induced effects could be found when the $K_{d}$ of the unirradiated reference was high. This can perhaps be explained by the fact that $\mathrm{Co}^{2+}$ sorbs through a closerange surface complexation interaction whereas $\mathrm{Cs}^{+}$mainly undergoes sorption through ion-exchange, and competes with the large excess of $\mathrm{Na}^{+}$which also may override a small induced radiation effect. Furthermore, a radiation induced decrease of $K_{d}$ was found in both pre-irradiated and dehydrated samples, as in saturated samples. This implies that $\gamma$-radiation can induce direct effects in the montmorillonite particles.

\subsection{Diffusion results}

In order to evaluate effects of $\gamma$-radiation on $\mathrm{Cs}^{+}$and $\mathrm{Co}^{2+}$ retention in the compacted and saturated clay materials it was found sufficient to model the apparent diffusivity $D_{a}$, qualitatively, using both an analytical method and a numerical method, the latter taking filter effects into account. For the analytical solution, the following equation was used (Crank, 1975) describing diffusion from a 'semi-infinite' source.

${ }^{A} A_{0}=\operatorname{erfc} \frac{x}{2 \overline{D_{a} T}}$

Furthermore, in order to obtain the apparent diffusivity values and the implicit $K_{d}$ values from the experimental concentration profiles in the clay plugs as well as from the breakthrough data $\left(\mathrm{Cs}^{+}\right.$only) while at the same time taking the diffusive resistance of the end filters into account, a finite-difference code called ANADIFF was used, see (Eriksen et al., 1999) for details. The water content of all the SwyNa $\mathrm{w}_{w}$ and MX80 samples as controlled gravimetrically after termination of the in-diffusion experiment was $1.39 \pm 0.05$ and $1.64 \pm 0.04 \mathrm{~g} / \mathrm{cm}^{3}$, respectively. Figure 4 shows typical concentration profiles of $\mathrm{Co}^{2+}$ and $\mathrm{Cs}^{+}$in the clay plugs together with the corresponding simulated data obtained using the ANADIFF code, see Table 1. The different simulated data, shown as dashed curves shows the effect of $K_{d}$ values varying by a factor of 2 , both increasing and decreasing. Figure 5 shows a comparison between the implicit $K_{d}$ values for $\mathrm{Cs}^{+}$obtained from ANADIFF and the corresponding values obtained in the batch sorption experiment. Since breakthrough of $\mathrm{Co}^{2+}$ did not occur during the course of the diffusion experiment, accurate determination of the implicit $K_{d}$ values for $\mathrm{Co}^{2+}$ with ANADIFF was not possible, since the impact of $K_{d}$ on the concentration profile of $\mathrm{Co}^{2+}$ is negligible compared to the $D_{a}$. This is illustrated in Figure $4 \mathrm{a}$, with the dashed simulated curves being almost perfectly overlaid showing that the $K_{d}$ value of $\mathrm{Co}^{2+}$ altered by a factor of 2 does not affect the concentration profile in the clay plugs. In the case of $\mathrm{Cs}^{+}$, no significant difference between the $K_{d}$ values as obtained from ANADIFF and batch sorption experiments under different experimental conditions was found, except for the irradiated SwyNaw samples. This indicates that dispersed HS upon irradiation increases its affinity for $\mathrm{Cs}^{+}$, possibly due to degradation to lower molecular residues. On average, the $K_{d}$ values for the diffusion cell samples were slightly larger than the corresponding batch sorption values, $86 \pm 32 \mathrm{~cm}^{3} / \mathrm{g}$ 


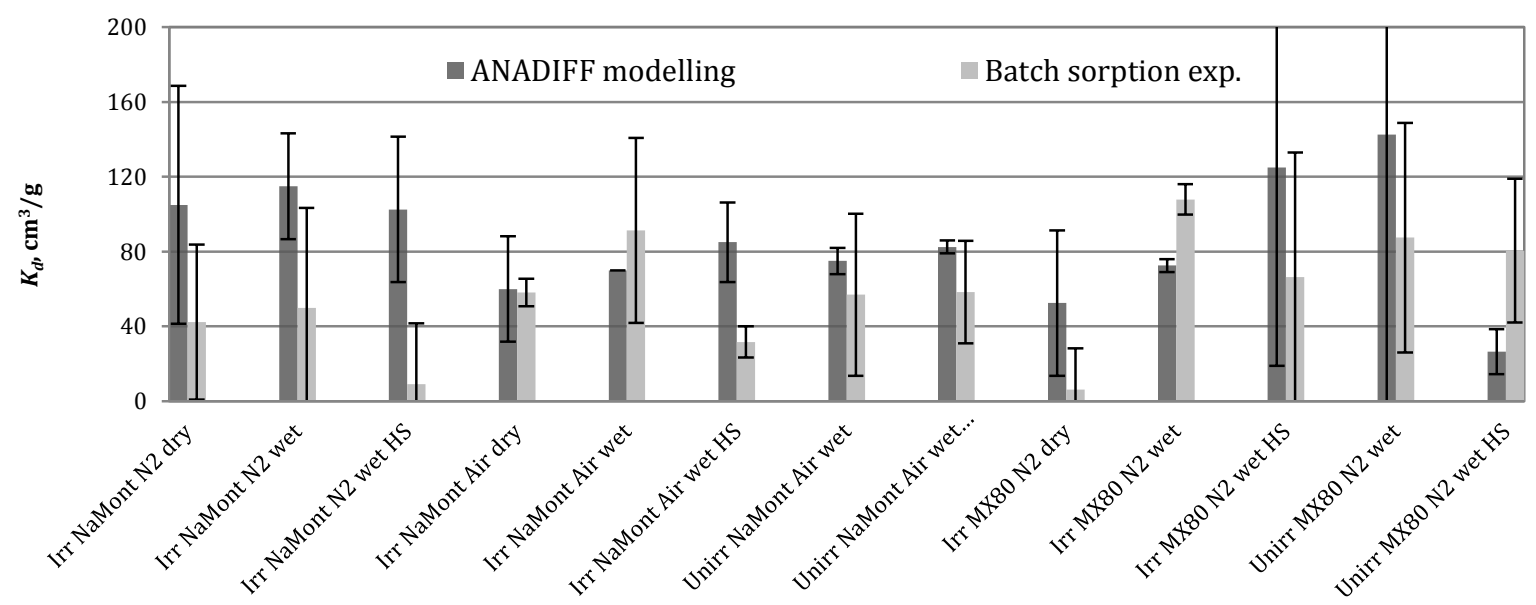

Figure 5. The averaged $K_{d}$ values $(\mathrm{n}=2)$ for $\mathrm{Cs}^{+}$obtained from the ANADIFF simulations (dark grey) compared to $K_{d}$ values obtained from the batch sorption experiment (light grey).
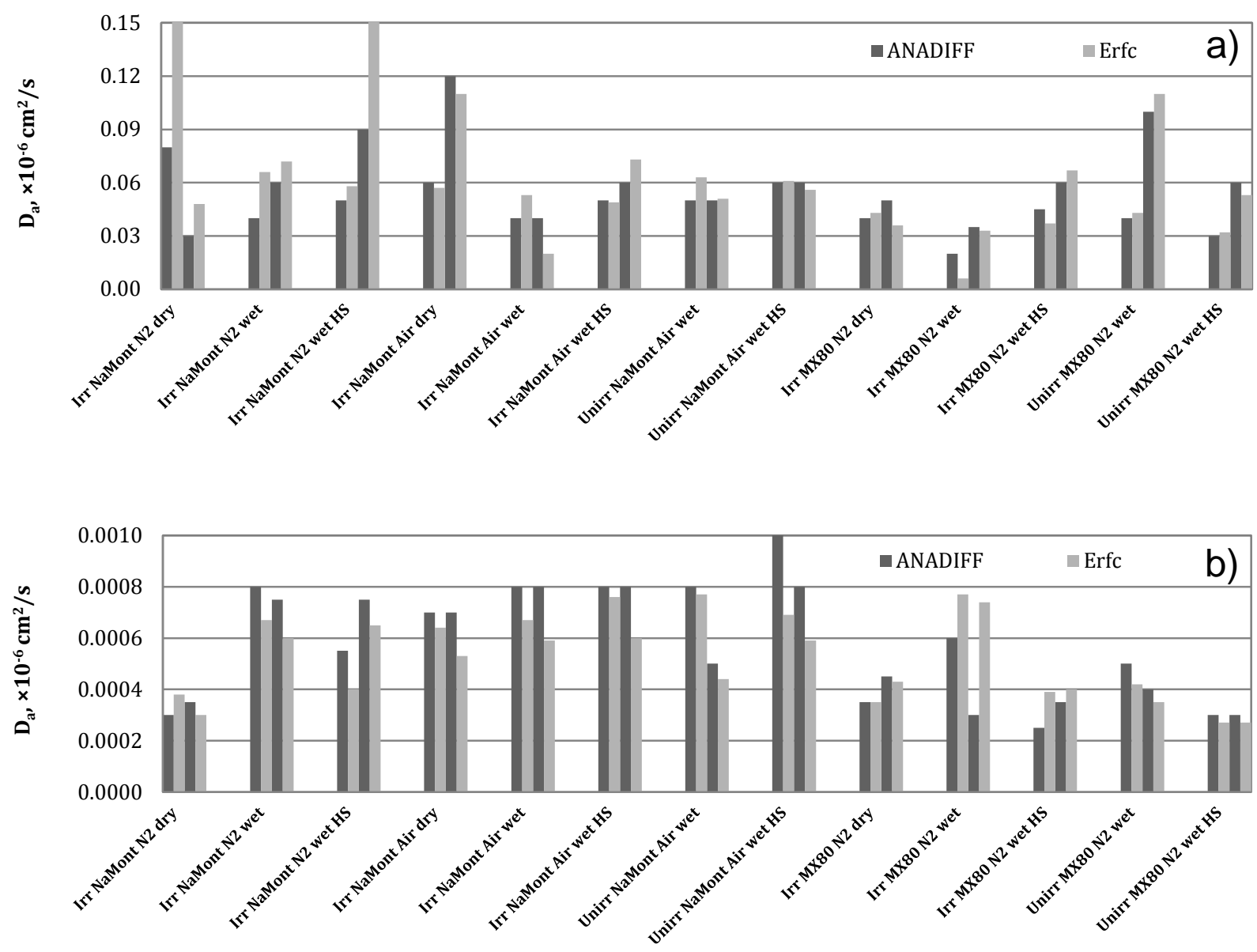

Figure 6. The $D_{a}$ values for $\mathrm{Cs}^{+}$(top) and $\mathrm{Co}^{2+}$ (bottom) obtained in the diffusion experiments, see Table 1 . The $D_{a}$ values are shown for each duplicate as obtained from ANADIFF (dark grey) and the error function, Equation 2 (light grey). 

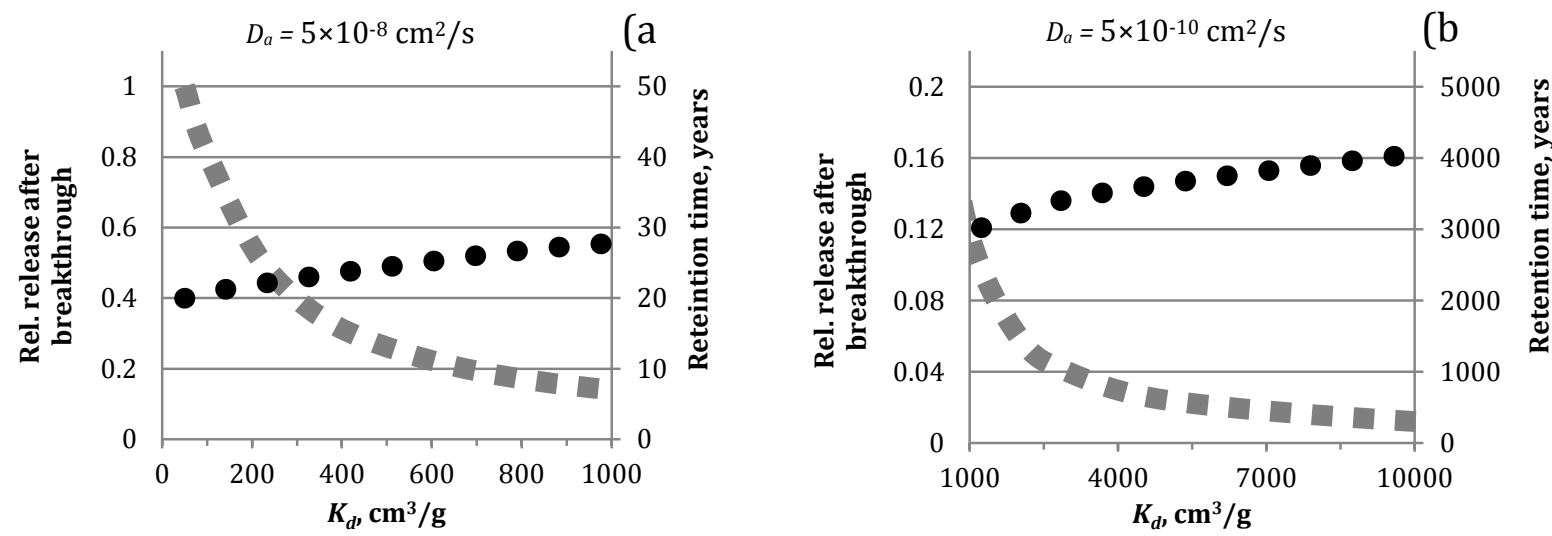

Figure 7. A comparison of hypothetical release through bentonite barrier as a function of $K_{d}$ with apparent diffusivity values of a) $5 \times 10^{-8} \mathrm{~cm}^{2} / \mathrm{s}$ and b) $5 \times 10-10 \mathrm{~cm}^{2} / \mathrm{s}$, respectively. The grey squares display the relative RN release vs. $K_{d}$ after breakthrough (left hand axis) whereas the black circles display the retention time in years before release $1 / 1000$ of the in-diffusing concentration.

and $57 \pm 30 \mathrm{~cm}^{3} / \mathrm{g}$, respectively. Thus, no apparent difference between the experimental and simulated $K_{d}$ values was found. The $D_{a}$ values for both $\mathrm{Cs}^{+}$and $\mathrm{Co}^{2+}$ obtained from ANADIFF and equation 2 are displayed in Figure 6 . As can be seen, the two methods revealed comparable $D_{a}$ values, and were also found to agree well with diffusion data in the literature (Molera and Eriksen, 2002). In general, the apparent diffusivities of $\mathrm{Co}^{2+}$ and $\mathrm{Cs}^{+}$were in the same order of magnitude in the irradiated and unirradiated samples (within a factor of 2).

Since the $D_{a}$ values and overall RN release depend on the amount RN's sorbed in the clay, the impact from an altered $K_{d}$ values on the RN retention was calculated with ANADIFF. The calculations were performed for a bentonite barrier thickness of $0.35 \mathrm{~m}$ and two hypothetical RN's with different $D_{a}$ values, $5 \times 10^{-8} \mathrm{~cm}^{2} / \mathrm{s}$ and $5 \times 10^{-10} \mathrm{~cm}^{2} / \mathrm{s}$, respectively. The resulting $\mathrm{RN}$ release is plotted in Figure 7, both in relative terms after breakthrough (left axis) and as the retention time, here defined as the time in years to release $1 / 1000$ of the inlet concentration (right axis). In terms of retention time, the impact of $K_{d}$ is relatively small. For 'fast' RN's (Figure 7a), having relatively small $K_{d}$ values $\left(<1000 \mathrm{~cm}^{3} / \mathrm{g}\right.$ ), the retention time only varies between 21-28 years for $K_{d}$ values of $100-1000 \mathrm{~cm}^{3} / \mathrm{g}$, i.e. an increase in retention time with $33 \%$ by a change in $K_{d}$ by a factor of 10 . For a 'slow' RN (Figure 7b) having a large $K_{d}$ value, ( $>1000 \mathrm{~cm}^{3} / \mathrm{g}$ ) the same relative change is observed for $K_{d}$ values between 1000$10000 \mathrm{~cm}^{3} / \mathrm{g}$, i.e. varying with a factor of 10 , although in absolute numbers the retention time is prolonged with 1000 years. Thus, with decreasing $D_{a}$ and increasing $K_{d}$, the impact of $K_{d}$ on the retention time before RN breakthrough increases.
Taking the radioactive decay into account, this effect would be even larger. In terms of relative release after breakthrough however, shown on the left hand axis in Figure 7a and Figure $7 \mathrm{~b}$ as normalized to a $K_{d}$ value of $50 \mathrm{~cm}^{3} / \mathrm{g}$, the amount of RN's released, is as expected proportional to the $K_{d}$ value, i.e. decreasing by a factor of nearly 2 if the $K_{d}$ value is halved, see also Figure 4c.

\section{Conclusions}

The effect on $\gamma$-radiation of radionuclide retention and sorption was investigated under different experimental conditions in batch sorption and diffusion experiments. Irradiation of MX80 and WyCa significantly decreased the sorption of $\mathrm{Co}^{2+}$ but not $\mathrm{Cs}^{+}$. This effect is also seen in the experiments with $\mathrm{WyNa}$, however not from irradiation under anoxic conditions. Thus, depending on the chemical environment, $\gamma$-radiation may alter the surface characteristics contributing to surface complexation of $\mathrm{Co}^{2+}$. For $\mathrm{Cs}^{+}$, the sorption was found to be comparable in irradiated and unirradiated clays. Hence, more obvious radiation induced effects could be found when the $K_{d}$ of the unirradiated reference was high. Furthermore, since the radiation induced decrease of $K_{d}$ was found in both pre-irradiated dehydrated samples as in irradiated saturated samples, the radiation induced decrease of $K_{d}$ might be caused by direct effects in the montmorillonite particles. Interestingly, irradiation under oxic conditions as well as treating the clay with $\mathrm{H}_{2} \mathrm{O}_{2}$ decreases the sorption capacity significantly. In the presence of HS, a larger part of $\mathrm{Co}^{2+}$ is complexed in the solution phase resulting in lower $K_{d}$ values towards the clays. On the 
contrary, $\mathrm{Cs}^{+}$is not affected by the presence of HS, probably since its low affinity to both the HS and clay surfaces anyway. As for the obtained apparent diffusivity values, the effect of decreasing sorption of $\mathrm{Co}^{2+}$ to the irradiated clays was unfortunately not large enough to be reflected under these experimental conditions. Furthermore, from ANADIFF simulations of RN transport through a realistic bentonite barrier (thickness $0.35 \mathrm{~m}$ ), the impact of altered $K_{d}$ values on the retention time before breakthrough was found to be small in relative terms but large in absolute number of years for slow RN's such as $\mathrm{Co}^{2+}$ having low $D_{a}$ values. In the overall RN release after breakthrough however, the relative amount of released RN was, as expected, found to be proportional to $K_{d}$.

\section{References}

Crank, J., 1975. The mathematics of diffusion, 2ed ed. Oxford University Press.

Eriksen, T.E., Jansson, M., Molera, M., 1999. Sorption effects on cation diffusion in compacted bentonite. Engineering geology 54, 231-236.

Holmboe, M., Jonsson, M., Wold, S., 2011. Influence of $\gamma$ radiation on the reactivity of montmorillonite towards $\mathrm{H}_{2} \mathrm{O}_{2}$. Submitted to Radiation Physics and Chemistry.

Holmboe, M., Wold, S., Jonsson, M., Garcia-Garcia, S., 2009. Effects of $\gamma$-irradiation on the stability of colloidal $\mathrm{Na}^{+}$Montmorillonite dispersions. Appl. Clay Sci. 43, 86-90.

Huang, W.H., Chen, W.C., 2004. Swelling behavior of a potential buffer material under simulated near field environment. Journal of Nuclear Science and Technology 41, 1271-1279.

Karnland, O., Olsson, S., Nilsson, U., 2006. Mineralogy and sealing properties of various bentonites and smectite-rich clay material. SKB AB, Swedish Nuclear Fuel and Waste Management Co.

Kozaki, T., Fujishima, A., Sato, S., Ohashi, H., 1998. Selfdiffusion of sodium ions in compacted sodium montmorillonite. Nucl. Technol. 121, 63-69.

Kozaki, T., Inada, K., Sato, S., Ohashi, H., 2001. Diffusion mechanism of chloride ions in sodium montmorillonite. J. Contam. Hydrol. 47, 159-170.

Molera, M., Eriksen, T., 2002. Diffusion of $22 \mathrm{Na}^{+},{ }^{85} \mathrm{Sr}^{2+},{ }^{134} \mathrm{Cs}^{+}$ and ${ }^{57} \mathrm{Co}^{2+}$ in bentonite clay compacted to different densities: experiments and modeling. Radiochimica Acta 90, 753-760.

Negron, A., Ramos, S., Blumenfeld, A.L., Pacheco, G., Fripiat, J.J., 2002. On the Structural Stability of Montmorillonite Submitted to Heavy $\gamma$-irradiation. Clay. Clay. Miner. 50, 35.

Plötze, M., 2003. Alteration of clay minerals - gammairradiation effects on physicochemical properties. Appl. Clay Sci. 23, 195-202.

Plötze, M., Kahr, G., Stengele, R.H., 2002. Alteration of clay minerals in long-term nuclear waste repositories influence on physicochemical properties. 325.

Pusch, R., Karnland, O., Lajudie, A., Decarreau, A., 1993. MX 80

clay exposed to high temperatures and gamma radiation. SKB AB, Swedish Nuclear Fuel and Waste Management Co.

Pushkareva, R., Kalinichenko, E., Lytovchenko, A., Pushkarev, A., Kadochnikov, V., Plastynina, M., 2002. Irradiation effect on physico-chemical properties of clay minerals. Appl. Clay Sci. 21, 117-123.

Stucki, J.W., Golden, D.C., Roth, C.B., 1984. Effects of reduction and reoxidation of structural iron on the surface charge and dissolution of dioctahedral smectites. Clay. Clay. Miner. 32, 350-356.

Van Loon, L., Glaus, M., Muller, W., 2007. Anion exclusion effects in compacted bentonites: Towards a better understanding of anion diffusion. Appl. Geochem. 22, 25362552.

Wold, S., Eriksen, T., 2007. Diffusion of humic colloids in compacted bentonite. Phys. Chem. Earth. 32, 477-484. 


\section{Supplementary material}

Table S.1. Summary of the $K_{d}$ values for $\mathrm{Co}^{2+}$ in $\mathrm{cm}^{3} / \mathrm{g}$, obtained from the batch sorption experiment.

\begin{tabular}{l|c|c|c|c|} 
& $S w y N a_{w} \mathrm{pH} 9$ & std. dev. & $S w y N a_{w} \mathrm{pH} 9+C a$ & std. dev. \\
\hline$\gamma$, dry, $N_{2}$ & 390 & 40 & 490 & 170 \\
$\gamma$, dry, Air & 440 & 30 & 560 & 40 \\
$\gamma$, wet, $N_{2}$ & 410 & 40 & 460 & 50 \\
$\gamma$, wet, Air & 510 & 10 & 610 & 30 \\
$\gamma$, wet, $N_{2}, H S$ & 280 & 50 & 390 & 80 \\
$\gamma$, wet, Air, HS & 420 & 50 & 530 & 100 \\
No $\gamma, N_{2}$ & 350 & 10 & 440 & 90 \\
No $\gamma, N_{2}, H S$ & 390 & & 560 & 140 \\
\hline
\end{tabular}

\begin{tabular}{|c|c|c|c|c|}
\hline & WyNa pH 9 & std. dev. & WyCa pH 9 & std. dev. \\
\hline$\gamma, d r y, N_{2}$ & 950 & 30 & 7470 & 510 \\
\hline$\gamma, d r y, A i r$ & 970 & 50 & 9470 & 210 \\
\hline$\gamma$, wet, $N_{2}$ & 2570 & 280 & 7880 & 960 \\
\hline$\gamma$, wet, Air & 730 & 160 & 9450 & 1570 \\
\hline$\gamma$, wet, $N_{2}, H S$ & 1960 & 220 & 3640 & 330 \\
\hline$\gamma$, wet, Air, HS & 630 & 100 & 4380 & 240 \\
\hline $\mathrm{No} \gamma, N_{2}$ & 2800 & 230 & 13300 & 740 \\
\hline No $\gamma, N_{2}, H S$ & 980 & 10 & 4580 & 110 \\
\hline
\end{tabular}

\begin{tabular}{l|cc|cc|} 
& $M X 80 \mathrm{pH} 9$ & std. dev. & $M X 80 \mathrm{pH} 9+C a$ & std. dev. \\
\hline$\gamma$, dry, $N_{2}$ & 7130 & 500 & 5860 & 430 \\
$\gamma$, wet, $N_{2}$ & 6570 & 350 & 5960 & 450 \\
$\gamma$, wet, $N_{2}, H S$ & 3010 & 10 & 2390 & 150 \\
No $\gamma, N_{2}$ & 13190 & 820 & 9630 & 1310 \\
No $\gamma, N_{2}, H S$ & 3510 & 770 & 2580 & 490 \\
\hline
\end{tabular}

